\title{
ASÍ EN LA CORTE COMO EN EL CIELO. PATRONATO Y CLIENTELISMO EN LAS COMUNIDADES CONVENTUALES MADRILEÑAS (SIGLOS XVI-XVIII) ${ }^{1}$
}

\author{
por
}

JESÚ́ IZQUIERDO MARTÍN, JOSÉ MIGUEL LÓPEZ GARCÍA, JUAN FRANCISCO MARTÍN DE LAS MULAS REGUILLO, RAFAEL. MÉNDEZ SASTRE, GUADALUPE MORENO LÓPEZ Y JOSÉ IUIS DE PABLO GAFAS.

Equipo Madrid de Estudios Históricos (Universidad Autónoma de Madtid).

RESUMEN: En las uiltimas décadas, el análisis de las relaciones patronorliente se ba con. vertido en tema recurrente dentro de la bistoria social. No obstante, la mayoria de las investigaciones omite que diferentes estructuras económicas bistóricas definieron los limites y formas de dichas relaciones. Como apoyo a este planteamiento teórico, el presente trabajo investiga la dinamica reproductiva de las comunidades conventuales de Madrid durante la época moderna a través de la configuración de un complejo y específico entramado de relaciones clientelares, de base urbana. Para ello, bemos recurrido al empleo de un fuente novedosa: las escrituras de fundación de misas y memorias perpetuas de siete comunidades religiosas de Madrid. Su estudio permite explicar no sólo las modificaciones que a largo plazo se produjeron en la composición sacial de las clientelas conventuales, sino también sus repercusiones sobre la estructura patrimonial y rentista del clero regular madrileño, basta su declive inexorable en las postrimerias del Antiguo Régimen.

Palabras Clave: Parentesco-patronato-clientelismo. Órdenes religiosas. Madrid. Historia moderna urbana. Sociedad cortesana.

ABSTRACT: In recent decades, the analysis of patron-slient relations bas become a recurring theme within Social History. However, the mayority of investigations does not take into account the fact that differing historical economic structures defined the limits and forms of these relationships. To support this theory, the present study investigates the self-reproductive dynamics of the Madrid religious orders during the Early Modern Period through the complex and specific urban based

1 El original de este trabajo, que ha sido actualizado para esta edición, fue presentado al II Congresso Italo-Ibero di Demografia Storica, celebrado en Savona (Italia) en 1992. 
network of client relations. To do this, we bave resorted to the use of an innovative source: the chursh memorial service records of seven religious communities in Madrid. Their study allows us to explain not only the long-term modifications produced in the social composition of the convent clients, but also their repercussions on the patrimonial and finacial structure of the urban regular clergy until their inexorable decline in the aftermath of the Ancien Régime.

KEY wORDS: Kinship-patron-client relations. Religious orders. Madrid. Urban early modern history. Court society.

En las últimas décadas, el análisis de las relaciones patrono-cliente se ha convertido en uno de los temas preferidos por los cultivadores de la historia social. Sin embargo, las herramientas conceptuales que se han utilizado para caracterizar este tipo de relación social (patronazgo, clientelismo, parentesco artificial) han sido producto de un trasvase escasamente crítico de ciertos paradigmas antropológicos y sociológicos que han contribuido a afianzar aún más el análisis individualista y funcionalista que domina el actual panorama historiogtáfico. Sin lugar a dudas, la ausencia de método analítico y un profundo eclecticismo han desembocado en que el concepto patrono-cliente se haya convertido en la panacea que permite explicar hs relaciones básicas imperantes en la Historia desde el Mundo Antiguo hasta la época contemporánea ${ }^{2}$.

En efecto, al considerar las relaciones clientelares como una interacción sustentada en un intercambio individualista e intencional y al hacer de esta concepción el núcleo explicativo básico de toda dinámica social, la sociedad queda reducida a un mero agregado de intereses y voluntades personales que confluyen consensuadamente en un mundo sin conflictos. Esta imagen idilica, tan estimada por ciertas escuelas historiográficas y en la que el cambio social queda reducido a una disfunción coyuntural, hace posible que este concepto de clientela sea aplicable a cualquier formación social, ya sea del pasado o presente, lo que indefectiblemente conduce a una visión estática de la historia ${ }^{3}$.

Ahora bien, si partimos de los presupuestos del materialismo histórico y convenimos en que es la estructura económica -conjunto de relaciones de pro-

2 Por lo que se refiere al predominio del funcionalismo en el estudio de las clientelas,vid. P. SÁNCHEZ LEÓN, «Nobleza, estado y clientelas en el feudalismo. En los límites de ba historia sociab, en S. CASTLLo (Coor), La Historia Social en España. Actualidad y perspectivas, Madrid, 1991, pp. 197-215. Ejemplos representativos de esta visión historiográfica relativa a las redes clientelares son J.F. MEDARD, «Le rapport de clientèle: du phénomène sociale à l'analyse politique», en Revue Francaise de Ciente Politique, XXVI, 1976, pp. 103-131; J. ScoTr; «Patronazgo, o explotación?h, en E. GELLNER y ottos, Patronos y clientes en las rociedades mediterráneas. Madrid, 1986, pp. 34-61; M.A. BeIRANTE, «Os diferentes tipos de solidaridades na cidade medieval. $O$ exemplo de Evoras, en Actas de las I Jornadas de cAtrqueologia do Estado». Lisboa, 1988, Vol. I, pp. 41-53 y la colección de trabajos compilados por A. REDONDO, Les parentés fictives en Espagne XVIleXVIIIe siècless). París, 1988. Una critica al individualismo metodológico en M. DouGlAs, Como piensan las instituciones. Madrid, 1996.

3 A este respecto puede verse R. Mousnier, «Les fidélités et les clientèles en France aux XVle, XVIIe, XVIIle siècles». Histoire Sociale, 15, 1982, pp. 36-46; Y. Durand (Ed.), Hommage

Hipania, LIX/1, núm. 201 (1999) 149-169 
ducción- la que determina en último extremo las formas adoptadas por las demás relaciones sociales, concluiremos que las clientelares, como relaciones no productivas, adoptaron unos caracteres específicos que variaron a lo largo del tiempo. Desde esta perspectiva, definiremos las relaciones clientelares como una forma de reciprocidad asimétrica e interpersonal entre agentes que por el hecho de poseer un estatus social similar intercambian recursos (fuerzas productivas, rentas, poder político, contenidos ideológicos) con objeto de conservar o mejorar sus posiciones económicas y políticas. Estos vínculos se explicarían en último extremo por una estructura económica que determina la posición objetiva de quienes la protagonizan ${ }^{4}$.

Como hemos señalado, la modificación de su forma, el peso objetivo de sus contenidos y la posición relativa de esta relación respecto de la estructura económica varió sustancialmente en cada modo de producción. Así por ejemplo, si nos centramos en el marco de las sociedades feudales que se desarrollaron en Europa desde el siglo X al XVIII, es posible constatar la presencia de unas relaciones clientelares singulares, que experimentaron modificaciones cualitativas a partir de la resolución de la crisis bajomedieval. Durante el mencionado arco temporal, las relaciones serviles de producción se caracterizaron por la ausencia de poder efectivo total de los agentes sociales sobre las fuerzas productivas, lo que hizo que los procesos de acurnulación y explotación fueran eminentemente políticos, adoptasen formas dispersas y necesitaran de aparatos y discursos ideológicos que los afianzasen.

Fue precisamente este peso específico de las superestructuras, y consecuentemente la forma adoptada por el Estado en este modo de producción, lo que obligó a la clase feudal a utilizar profusamente unas redes clientelares que le permitieran interconectar todas sus organizaciones y recursos para hacer efectivo el dominio y la explotación sobre los productores directos. Este clientelismo social, con objetivos eminentemente políticos, modificó su forma e intensificó su presencia a medida que se fueron transformando las estructuras económicas y complejizando las tecnologías de dominación, en el paso de las Edades Media a la Moderna 5 .

En este contexto, la Iglesia feudal fue una de las fuerzas motrices que impulsaron el desarrollo del sistema en su conjunto. La simbiosis entre la Iglesia y las Monar-

à Roland Mousnier. Clienteles et fidélités en Europe à l'épogue moderne. París, 1981.Una critica a esta interpretación historiográfica en F. DOsSe, La bistoria en migajas. De «Annalesw a la «Nueva Historia». Valencia, 1988.

4 Para elaborar esta definición nos hemos basado fundamentalmente en $G$. A. COIIEN, $L a$ teoria de la Historia de Karl Marx. Una defensa. Madrid, 1986; E.O. WRIGIT, Clase, crisis y estado. Madrid, 1978; G. Therborn, 2 Cómo domina la clase dominante? México, 1979. Asimismo, nos han sido de utilidad las observaciones contenidas en S. KetrerING, Patrons, Brokers and Clients in Seventeenth-Century France. Nueva York, 1986; A. MACZAK, introducción a «Padrini e clienti nell' Europa moderna (secoli XV-XIX)», Cheiron, 5, 1986, pp. 5-8 y M.GILSENAN, «Contra las relaciones patrono-cliente», en E. GeL_NER y otros, Patronos..., pp. 153-176.

5 Sobre este tipo de Estado basado en la articulación de clientelas, véase A. Torre, Stato e società mell' Ancien Régime. Turín, 1983, pp. 153 y ss.; los trabajos contenidos en el monográfico 
quías feudales fue más allá del puro apoyo ideológico en unas formaciones sociales que precisaban estructuralmente de una profunda ideologización, al generar unos aparatos no discursivos (instituciones, recursos, organizaciones, estructuras jerárquicas) que contribuyeron a la consolidación del propio orden feudal ${ }^{6}$. A este respecto, la Iglesia, al postular la supremacía ideológica del parentesco artificial espiritual y articularlo en torno a sus aparatos no discursivos, favoreció el desarrollo de redes clientelares más complejas que sobrepasaban el marco estrictamente feudo-vasallático ${ }^{7}$.

El caso castellano, con sus específicas características estructurales, constituye un buen ejemplo de cuanto venimos diciendo. Como consecuencia de la rápida expansión territorial de los reinos cristianos, el feudalismo castellano estuvo desde sus orígenes determinado por un profundo desequilibrio de sus fuerzas productivas y una notable pujanza de las libertades campesinas, lo que dio lugar a una cierta laxitud en sus relaciones de producción. Son precisamente estos condicionamientos productivos y estructurales los que provocaron la temprana aparición de complejos aparatos políticos e ideológicos (señorios concejiles, señotíos monásticos, una poderosa Monarquía feudal con su Iglesia propia) destinados a responder desde la superestructura política a la debilidad originaria de las relaciones sociales de producción mediante acciones institucionalizadas y normalizadas de extracción de plustrabajo campesino. El carácter pronunciadamente bifrontal de los aparatos políticos castellanos -tendencialmente centralizados y descentralizadoshizo que las relaciones patrón-cliente fueran de capital importancia para la articulación de aquéllos".

A partir del siglo XV, la formación social castellana experimentará una paulatina "reacción feudal» que se acentuará a fines de la centuria siguiente y se ca-

de Cheiron, ya citado; G. Rosso, «Stato e clientele nella Francia della prima età modernan, Studi Storici, 1, 1987, pp. 37-82; R. D. LITCHFIELD, Emergence of a Bureawcracy. The Florentine Patricians. 1530-1790. Princeton, 1987; R. AGo, Carriere e clientele nella Roma barocta. Roma-Bari, 1990; W. REINHARD (Dir), Les ellites du povoir et la constrution de l'État en Europe. Paris, 1996 y J. MARTfNEZ MILLAN, "Las investigaciones sobre patronargo y clientelismo en la Administración de la Monarguia Hispana durante la Edad Modernas. Studia Historica, 15:3, 1996, pp. 83-106.

6 Vid. E. H. KanTokowicz, Los dos cuerpos del Rey. Un estudio de teologia politica medieval. Madrid, 1985; G. DuBY, Las tres óndentes o lo imaginario del feudalismo. Barcelona,1983; А. Gulueziau, El feudalismo. Un borizonte teórico. Barcelona, 1984, pp. $229-249$ y G. Bors, La revolución del año mil. Barcelona, 1991, pp. 81 y ss. Sobre la necesidad estructural de las ideologias para legitimar los sistemas sociales, vid. N. ABERCROMi3ie, S. Hud. y B. S. TuRner, La tesis de la ideologia dominante. Madrid, 1987, passim; finalmente sobre la determinación material de la ideología y la distinción entte aparatos ideológicos discursivos y no discursivos, vid. G. TrierBonn, La ideologia del poder y el poder de la ideologia. Madrid, 1987, pp. 26-56.

7 Véase S.D. WHITE, Custom, Kinsbip and Gifts to Saints. The Laudatio Parentum in Western France. 1050-1150. Chapel Hill-Londres, 1988. Una sintesis sobre esta cuestión puede encon-

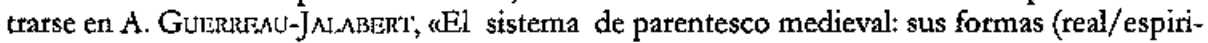
tual) y su dependencia con respecto a la organización del espacion, en R. PASTOR (Comp.), Relaciones de poder, de production y parentesco en la Edad Media y Moderna. Madrid, 1990, pp. 85-105.

8 Para una visión de conjunto sobre el proceso de expansión del feudalismo medieval castellano, vid. A. MACKAY, La España de la Edad Media. Desde la Frontera basta el Imperio

Hipqania, J.JX/1, núm. 201 (1999) 149-169 
racterizará por cambios sociales estructurales (aumento paulatino de la clase feudal y su poder efectivo sobre los productores directos) y una cierta complejización de las organizaciones políticas, que paradójicamente fue simultánea a un proceso de patrimonialización de los cargos por parte de la clase dominante, quebrando de esta forma las líneas que desde el reinado de los Reyes Católicos apuntaban hacia una relativa burocratización del Estado. Este proceso de intensa socialización de lo político dio lugar a que has redes clientelares, destinadas a captar recursos personales, tuvieran una capital importancia en la Corte que quedará radicada en Madrid desde el reinado de Felipe II 9 .

Por razones obvias, la simbiosis Monarquía-Iglesia a la que hemos aludido fue excepcionalmente intensa en Castilla, dado que durante el proceso de expansión y consolidación de su formación feudal los eclesiásticos aportaron tanto el discurso ideológico imprescindible para combatir al infiel, como las organizaciones y recursos necesarios para asentar las bases de un nuevo orden social ${ }^{10}$.

Ahora bien, por su estructura jerarquizada, la estabilidad de sus tecursos y su contribución a la difusión de la reforma gregoriana, las órdenes monásticas constituyeron . los medios más efectivos de vertebración feudal del espacio recién conquistado. Por este motivo, nada tiene de extraño que fuesen los monatcas castellano-leoneses los primeros interesados en fomentar la fundación de enclaves cluniacenses y cistercienses desde los aledaños de la Cornisa Cantábrica al valle del Duero "1. Sin embargo, estas instituciones tuvieron desde sus orígenes una específica característica estructural expresada en la debilidad de su poder político a la hora de hacer efectivos los

(1000-1500). Madrid, 1985; H. FREY, La feudalidad europea y el régimen señonial español. México, 1988 y En torno al feudalismo bispano. I Congreso de Estudios Medievales. Madrid, 1989. De la muy abundante y reciente bibliografia relativa a la relación existente en Castilla entre feudalización y desarrollo concejil dan cuenta los diferentes artículos compilados en Concejos y Ciudades en la Edad Media Hispánica. II Congreso de Estudios Medievales. Madrid, 1990. Y sobre la dinámica política seguida por el estado feudal castellano, vid. J. M. MonsALvo ANTón, «Poder político y aparatos de Estado en la Castilla bajomedieval. Consideraciones sobre su problemática». Studia Historica, IV: 2, 1986, pp. 101-167.

9 La biografia de algunos señeros personajes incardinados en las clientelas cortesanas, en J. Martínez MILúín (dir.), La Corte de Felipe II. Madrid, 1994.

10 A este respecto véase A. RODRIGUEZ LOPEZ, iLa politica eclestästica de la monarquía castellano-leonesa durante el reinado de Fernando III (1217-1252)", Hispania, XLVIII, 168, 1988, pp. 7-48; E. PASCUA EchEGARAY, "Hacia la formación politica de la monarquia medieval. Las relaciones entre la monarquia y la iglesia castellano-leonesa en el reinado de Alfonso VIL, Hispania, XIIX, 172, 1989, pp. 397 441 y la colección de trabajos compilados en Etat et Eghise dans la genèse de l'Etat moderne. Madrid, 1986.

11 Sobre la feudalización realizada por las órdenes monásticas al Norte del Duero, vid. S. Moret VeLAyos, El monasterio de San Pedro de Cardeña. Historia de un dominio castellano (902-1338). Salamanca, 1971; I. ALFONSo ANTón, La colonización cisterciense en la meseta del Duero. El dominio de Morerzela (siglas XII-XIV). Salamanca, 1986 y de la misma autora "Cistercians and Feudalism". Past and Present, 133, 1991, pp. 3-30. Finalmente, J. M. Lopez Garcí, La transición del feudalismo al capitalismo en un señorio monástico castellano. El abadengo de la Santa Espina (1147-1835). Valladolid, 1990. pp. $311-325$. 
procesos de acumulación y explotación sobre sus campesinos dependientes, dado que sólo contaban con una autoridad momal reconocida que no se correspondía con una capacidad de coacción fisica propia. Dicha debilidad estructural se tradujo en la contradicción que supuso el que para hacer efectivos ambos procesos se vieran obligadas a apoyarse, a través de sólidas redes clientelares, en otros poderes feudales (Monarquía, concejos, aristocracia..) con los que finalmente entrarín en intensa competencin en un proceso cada vez más agudo de reacción feudal ${ }^{12}$.

Los efectos de dicha contradicción pronto quedarían manifiestos en la propia expansión del feudalismo castellano. En este sentido, una vez organizados y feudalizados los espacios situados en la zona septentrional de la península, la formación social castellana proseguirá su expansión hacia el sur por unos cauces de naturaleza bien distinta. En esta nueva etapa, que culminará en el siglo XIII, la Monarquía asumirá una dirección más enérgica de los desarrollos expansivos, pasando la mayoría del peso de las nuevas conquistas a unos aparatos políticos, los concejos, mucho más eficaces que los dominios monásticos en la dinámica de estructuración feudal -por su potencial y más compleja integración de clase dominante- y de articulación en tomo a la corona -por su eficiencia extractora de excedente que permitía la participación en el mismo de la Monarquía sin graves tensiones-. El nuevo peso específico de estos aparatos en un primer momento, asi como el protagonismo alcanzado posterioumente por otras organizaciones con grandes tecursos políicos directos, como las órdenes militures, explican la paulatina pérdida de importancia de los antiguos señorios monásticos para el propio poder monárcquico.

$\mathrm{Si}$ a esto añadimos la derrota que en el Norte del Duero y en una sociedad cada vez más feudalizada sufrió la vía que había permitido la expansión de estos dominios monásticos mediantel a acumulación y explotación directas de fuerzas productivas con recursos políticos indirectos, comprenderemos los dos resultados claves de la salida bajomedieval experimentada por el clero regular.

Por un lado, las órdenes religiosas altomedievales se vieron obligadas a paralizar la expansión de su poder efectivo parcial sobre sus patrimonios y a consolidarlo mediante procesos tendentes a la gradual «absolutizaciónv de sus propiedades o a la organización de sus economías a través de vías de apropiación indirecta (desarrollo de las cabañas estantes, trashumantes, etc. ${ }^{13}$.

Por otro, tanto al Norte como al Sur de Castilla las nuevas fundaciones conventuales bajomedievales y modernas manifestaron un carácter cualitativamente distinto al de los monasterios de la Alta Edad Media. En efecto, con

12 Una de las instituciones particulares a través de las cuales los monasterios quedaron supeditados a la nobleza laica fue la de la encomienda. A este respecto, vid. J. SANTos Diez, La encomienda de monasterios en la corona de Castilla. Siglos X al XV. Roma-Madrid, 1981 y J. PÉlez:L-EMBID, E/Cister en Castilla y León. Monacato y dominios rurales (ss.XII-XV). Salamanca, 1986, pp. 561573 .

13 Con respecto al protagonismo de concejos, vid. J.M. MONSALvo ANTÓN, «Transformaciones sociales en los concejos de frontera, siglos XI-XIII. Aldeanos, vecinos y caballeros ante las instituciones municipales", en R. PASTOR (Comp.), Relaciones..., pp. 107-170. Sobre la adquisición del dominio pleno sobre la propiedad de la tierra y la formación de cotos redondos, vid. J.M. LOPEZ.

Hipania, LIX/1, núm. 201 (1999) 149-169 
limitadas posibilidades de competir en la apropiación directa y en un contexto de crecimiento económico que, desde el siglo XII, fue paralelo a un aumento de la clase feudal, a un incremento de su poder efectivo y, consiguientemente, a una paulatina elevación de las tensiones interfeudales, la natutaleza del nuevo clero regular hubo de ser necesariamente urbana. De esta forma, en esta nueva etapa del feudalismo castellano, la posición objetiva del clero regular cambió tanto en el interior de la estructura económica como en el de la propia superestructura, quedando definitivamente relegado al espacio de los canales de explotación y acumulación indirectos -distribución centralizada de la renta feudal-a cambio de su progresiva especialización como ideólogo de la articulación horizontal de la clase dominante. Así pues, frente al papel hegemónico que los cenobios altomedievales desempeñaron en una primera feudalización de la tierra, las nuevas órdenes mendicantes se encontrarán ahora radicalmente subordinadas al conjunto de poderes feudales que impulsaron la nueva vertebración de la formación social castellana ${ }^{14}$.

Las raíces urbanas de este nuevo clero definieron la importancia de sus redes clientelares, hecho que se agudizará aún más en el marco de la Corte de los Austrias. Entre 1600 y 1750 se crearon en Madrid 36 institutos religiosos, es decir, más de la mitad de los 67 existentes al concluir la época moderna. El cenit de este proceso se alcanzó durante los reinados de Felipe III y Felipe IV, cuando se constituyeron 29 comunidades de frailes y monjas; a partir de 1660 se produjo una ralentización de la dinámica fundacional, como lo demuestra el que hasta finales del Seiscientos tan sólo se creasen cinco. Por último, el siglo XVIII estaría caracterizado por una auténtica parálisis, dado que únicamente se erigieron ottos tres conventos. En total, entre 1660 y 1750 se fundaron h mitad de institutos que en las tres primeras décadas del XVII, lo que evidencia -bien a las claras- la notable inflexión iniciada durante el gobierno del último de los Austrias ${ }^{15}$.

GarCi, La transición..., pp. 46-52 y 202. Por lo que se refiere al aumento de las cabañas monásticas, vid. J.M. MiNGUEZ, "Ganadería, aristocracia y reconquista en la Edad Media castellana», en Hispania, 151, 1982, pp. 341-354 y E. GAvLLAN, El dominio de Párraces en el siglo XV. Un estudio sobre la sociedad feudal. Zamora, 1986, pp. 269-286.

14 Sobre las ótdenes mendicantes y su origen eminentemente urbano, vid. L. K. Llirile, Pobreza voluntaria y economia de beneficio en la Europa medieval. Madrid, 1983. Un análisis concreto de esta implantación se encuentra en A. RucQuol, Valladolid en la Edad Media. 2 vols., Valladolid, 1987, vol. II, pp. 276-289. La importancia que para las oligatquías urbanas cobraton estas nuevas fundaciones ha sido resaltada por J. BiLINKOFF, Ávila de Santa Teresa. La reforma religiosa en uno ciudad del siplo XVI. Madrid, 1993.

15 Más detalles sobre las características de esta dinámica fundacional, en J. IzQUICRDo Martín, J.M. López GARcí y otros, «La reforma de regulares durante el reinado de Carlos III. Una valoración a través del ejemplo madrileñom, en EQUIPo MADRID, Carlos III, Madrid y la Ilustración. Contradiciones de un proyecto reformista. Madrid, 1988, pp. 189-221, especialmente 191-192 y R. MÉNDEZ SASTRE, La propiedad inmobiliaria en una ciudad cortesana. El patrimonio del clero regular madrileño en los siglos XVII y XVIII. Madrid. Memoria de Licenciatura inédita defendida en la U.A.M. en 1993 y cLa estructura conventual de la ciudad, siglos XII-XIX» en S. MADRAZO MA-

Hispunia, LIX/1, núm. 201 (1999) 149-169 
¿Quiénes fueron los actores sociales que protagonizaron esta fase de fundaciones conventuales? A diferencia de lo acontecido en tiempos de Felipe II, el papel de los representantes de la burocracia real se redujo ostensiblemente, en tanto que los miembros de la realeza incrementaron su función de patronato al crear 8 institutos entre 1606 y $1750^{16}$. Pero aun siendo relevante este cambio, todavía lo es más el que los propios representantes de las órdenes religiosas -con 13 fundaciones-y los de la aristocracia -con otras tantas-constituyeran ahora los principales motores de esta dinámica expansiva.

Por lo que se refiere al clero regular, nada tiene de extraño que se sintiese atraído por el espacio cortesano, pues en su seno se podían establecer relaciones clientelares que no sólo posibilitasen el acceso a fracciones de renta feudal local y centralizada previamente captadas por las élites laicas y la Hacienda Real, sino que al mismo tiempo le aseguratan la obtención de los apoyos sociales y políticos imprescindibles para su mantenimiento y ulterior ampliación ${ }^{17}$. A la vez, el apogeo de los frailes dentro de la capital se vio favorecido por el desarrollo de una corriente ideológica, la del Barroco.

Esta última pretendía afianzar los principios de autoridad y jerarquización heredados del Medievo, a través de la fijación de unas pautas de comportamiento para cada uno de los grupos existentes dentro de la sociedad estamental que debía ser estática por definición. No en vano, el desarrollo de esta cultura conservadora se ha ligado al proceso de homogeneización religiosa acontecido en los territorios católicos en la época de la Contrarreforma que, como ya señalamos, dio lugar a la práctica de una religiosidad externa y ritualizada, en la cual el clero regular asumió un papel destacado. Por último, este clero constituye ahora, merced a la aplicación de las disposiciones tridentinas, un cuerpo relativamente homogéneo, en el que se integran las viejas órde-

Drazo y V. Pinto Crespo (dirs.), Madrid. Atlas histórico de la ciudad, siglos XI-XIX. Barcelona 1995 , pp. 312-323, pp. 37-39 y gráfico 99 , respectivamente.

16 De ellos, nada menos que 6 fueron erigidos bajo el patrocinio de Felipe IV. Cfr. R. MéNDLE SASTRE, La propiedad inmobiliaria..., p. 42.

17 En lo que respecta al espacio cortesano y a la redistribución de rentas operada en su ámbito, vid. P. ANDERSON, El estado absolutista. Madrid, 1979, pp. 30 y ss.; N. EliAs, I a saciedad cortesana. México, 1982; ; H.CH. EHALt, La corte di Vienna tra sei e settecento. Roma, 1984. Por lo que se refiere al caso madrileño, vid. J.M. López GArCín y S. MADrAzo, «A Capital City in the Feudal Order: Madrid from the Sixteenth to the Eigbteenth Centuryn, en P. Clark y B. Lepetit (eds.), Capital Cities and their Hinterlands in Early Modern Europe. Aldershot, 1996, pp. 119-142. y J.M. LópEZ GARcin (Dir), El impacto de la Corte en Castilla. Madridy su territorio en la Epoca Moderna. Madrid, 1998. $\mathrm{La}$ singladura del clero regular madrileño, en nuestro artículo «Religiosidad barroca y oligarquias urbanas: la estrategia del clero regular madrileñon, en S. Madrazo Madrazo y V. Pinto Crespo (eds.), Madrid en la Época Moderna: Espacio, saciedad y cultura. Madrid, 1991, pp. 265-301; R. MÉnDEZ SASTRE, "La estructura conventual de la ciudad, siglos XII-XIX» en S. Madrazo Madrazo y V. Pinto Crespo (dirs.), Madrid. Atlas bistórico de la ciudad, siglos XI-XIX. Barcelona, 1995, pp. 312-323.

Hitania, LIX/1, núm 201 (1999) 149-169 
nes monásticas, las mendicantes y las específicamente ligadas a la Reforma católica, con una marcada vocación urbana ${ }^{18}$.

En lo que respecta a la aristocracia, su pujanza fundacional fue -en último extremo-consecuencia de la ofensiva política que protagonizó durante el siglo XVII. En los puestos de cabeza de la nómina de patronos nobiliarios encontramos a los propios validos y sus clientelas. Así, el duque de Lerma llegó a patrocinar cuatro conventos situados en las cercanías de su residencia en el Prado. Como no podía ser menos, el linaje del Conde Duque trató de emular al de su insigne antecesor: su tía fundó el Noviciado de los Jesuitas y el propio don Gaspar tomó el patronato del Colegio de Santo Tomás; mientras tanto, su primo, el marqués de Leganés, hizo lo propio con el convento de San Basilio, donde finalmente fue enterrado, y uno de sus hombres de confianza, Jerónimo de Villanueva, procedió a la creación del de San Plácido.

Pronto, los representantes de la nueva nobleza de servicio siguieron la misma senda, con objeto de legitimar su ascenso social, de tal forma que incluso ciertos representantes de las familias de asentistas portugueses y genoveses, como el marqués de Monesterio -Octavio Centurión- o la baronesa Beatriz de Silveira, patrocinaton los conventos del Rosario y el de los Carmelitas Descalzos, más conocido por el título de su acaudalada mecenas. Lejos de declinar, el patronato aristocrático fue en aumento a partir de 1660, hasta el extremo de que a dicha clase corresponde la fundación de la mitad de los últimos cenobios creados en la Villa y Corte ${ }^{19}$.

Con estas fundaciones, la nobleza perseguía varios objetivos a parte de los meramente espirituales. Ante todo, el pattonato, al que estos mecenas accedian mediante la decisión de crear a sus expensas un convento y dotar de recursos duraderos a la comunidad en él establecido, suponía -para quien lo poseía-disponer de un vínculo más cercano a la divinidad. Este mecanismo, basado en la difusión de unas redes de parentesco artificial, cuyo origen se remontaba a la Edad Media, se completaba con la alianza familiar directa a través de la profesión de los hijos varones menores en sus claustros y con la donación de bienes al convento: todos estos elementos permitian extender a ottos grupos sociales la estrategia de captación de feligreses, meta de todas las actividades realizadas en este periodo por los regulares.

A la postre, para los nobles fundadores, el entrar a formar parte de estas clientelas suponía un paso adicional orientado a incrementar su prestigio dentro de la sociedad, al hacerse partícipes de la autoridad indiscutible de la Iglesia. Para ser efectiva esta asociación requería, además, publicidad: nada mejor que

18 Sobre Barroco y Contrarreforma, wid. H. OUTRAM EvENNE]T, The Spinit of the Counter-Reformation. Oxford, 1968; J A. Maravnsu, La cultura de/ Barrow. Madrid, 1975; R. DE Mno, uLideale eroico della santità nella Contronfformav en C. Russo (Ed), Società, Chiesa e vita rekgiosa nell «Ancien Règime. Nápoles, 1976, pp. 285-308; T. EGIDO, Las claves de la Reforma y la Contrarreforma. 1517-1648. Barcelona, 1991 y nuestro trabajo «Religiosidad..».

19 Un análisis pormenorizado de las fundaciones de la alta nobleza, en R. MénDEz SASIRE, La propiedad inmobitiaria.., pp. 41-44.

Hispania, J,IX/1, núm 201 (1999) 149-169 
plasmar este vínculo privilegiado en un fastuoso edificio, en cuya fachada figurase el escudo de armas del fundador junto al de la propia congregación a la cual pertenecía de modo que quedara patente para toda la sociedad, de ahí que -a diferencia de los monasterios medievales- todos estos conventos se insertasen plenamente en la trama urbana, especialmente en los barrios periféricos, donde la demanda espiritual no podia ser cubierta por las escasas parroquias allí existentes ${ }^{20}$.

La creación de conventos femeninos también guardaba una estrecha relación con la política de preservación patrimonial de los linajes fundadores. Por este motivo, en los ocho institutos de monjas que creó la nobleza en el siglo XVII ingresaton periódicamente numerosas mujeres de sus familias condenadas al celibato. Pata los patronos, la creación de estos centros religiosos de reclusión no sólo servía para conservar la hacienda y el honor de su Casa, sino que también constituía una verdadera obra de caridad, dado que en ellos sus hijas solteras podían llevar una vida acorde a su posición sin tener que recurrir a bodas con gentes de baja extracción social, lo que por fuerza tenía que contribuir a que sus fundadores se ganasen el cielo. De nuevo, en este punto, la propaganda desempeñaba un lugar destacado: siguiendo las instrucciones de $S a n$ Carlos Borromeo, estas casas femeninas se ubicaban en lugares que permitietan su aislamiento, aunque sin esconderlas, de manera que estuviesen separadas del contacto físico con el mundo exterior sin que éste pudiera dejar de conocer su presencia. De ahí que frecuentemente se sitúen en las calles secundarias de los barrios nobiliarios, en edificios que suelen estar emplazados al lado de los palacios de sus fundadores, para recalcar aún más el poder de éstos sobre el espacio urbano ${ }^{21}$.

La estructura patrimonial de los institutos de regulares madrileños posee una notable similitud con respecto a la de sus benefactores laicos, como consecuencia de la estrecha relación económica que entre ambos se había establecido. Dutante el siglo XVII, los conventos de la Trinidad, la Merced y Santa Clara poseían un patrimonio medio superior a los 600.000 reales. Dentro del mismo, al igual que ocurría en las haciendas de los regidores, los consejeros reales y diversas Casas de la nobleza de servicio, los censos consignativos desempe-

20 Las motivaciones de las fundaciones nobiliarias madrileñas y sus repercusiones en la ocupación del espacio urbano, en R. MÉNDEZ SASTRE, "La estructura conventual...", p. 314.

21 El papel de los conventos femeninos en la preservación de los bienes de las familias aristocráticas, en J. L. SÁNCHEZ LORA, Mujeres, conventos y formas de la religiosidad Barroca. Madrid, 1988 y R. MÉnDEZ SASTRE, La propiedad..., pp. 148-150. Sobre el significado de los mismos en la conservación del honor femenino y consiguientemente de los linajes nobiliarios, en S. CAVA.LO y S. CERUTt, "Onore femminile e controllo sociale della riproduzione in Piamonte tra Sei e Settecenton. Quaderni Storici, 44, 1980, pp. 346-383. Los planteamientos teóricos relativos al emplazamiento de las casas de monjas y su plasmación en el Madrid del Seiscientos, en G. ZalurI, "Monasteri femminili e città (secoli XV-XVIII)", en Soria d'Ttalia. Annali 9. La Cbiesa e il potere politico dal Medioevo all'età contemporanea. Turin, 1990, pp. 359-429 y R. MÉNDEZ SASIRE, "La estructura...", pp. 314-316 y plano 131.

Hi.pouria, LJX/1, núm. 201 (1999) 149-169 
ñaban un papel estelar, al representar el 64,17 por ciento de sus fuentes de ingresos, seguidos de los juros $(32,3$ por 100) y de los títulos de deuda municipal $(3,53)$.

De igual forma, en la centuria siguiente se aprecia una mayor diversificación de sus fuentes rentísticas. En los casos de los Agustinos Recoletos y el Carmen Calzado, propietarios de unas haciendas cuyo valor medio rebasaba el millón de reales, los censos consignativos (32,5 por 100), los efectos de Villa (17 por ciento) y, sobre todo, los juros con menos del 6, han visto reducido su papel dentro de su estructura patrimonial; por contra, las fincas urbanas, que en el siglo anterior no tenían relevancia, ejercen ahora un liderato incuestionable, al representar el 38,8 por ciento de sus bienes amortizados, al tiempo que las explotaciones rústicas, destinadas a cubrir el consumo de las casas matrices, irrumpen dentro de sus fuentes de recursos. Aunque en principio podria pensarse que estas transformaciones siguieron la estela de las operadas en las haciendas de sus benefactores, las causas de las mismas eran más profundas y se encontraban íntimamente ligadas al declive de los propios regulares en el mundo urbano 22 .

La clave explicativa de esta transformación ha de buscarse en la evolución de las redes clientelates de los conventos madrileños. Para determinar su dinámica a largo plazo, hemos analizado las escrituras de fundaciones perpetuas de memorias de misas correspondientes a 7 institutos de regulares ${ }^{23}$. La vertebración de sus redes clientelares se fundamenta en una misma matriz estructural: el espacio cortesano, como núcleo básico de captación y redistribución de renta feudal, fue el lugar donde el clero regular hubo de competir con otros grupos sociales en una situación de dependencia con respecto a aquéllos, a fín de participar en el proceso de apropiación del excedente.

Tal dependencia se materializó en dos vertientes concretas. Por una parte, la composición social de las comunidades religiosas se vio determinada por los continuos aportes demográficos -exógenos- de la clase dominante. Por otra, su propia estructura patrimonial siempre dependió de las donaciones tealizadas por aquélla, concretándose en una propiedad parcial e indirecta de derechos sobre el excedente basada en títulos de renta (ver

22 Los ingresos de estos cinco monasterios, en ibidem, pp. 320-321 y gráfico 103. Desde una perspectiva más general, C. CARo LópEZ, «Aproximación a las rentas de los regulares madrileños en los siglos XVIl y XVIII». Anales del Instituto de Estudios Madrileños, XXXVI, 1996, pp. 117-133.

23 La muestra escogida abarca una variada tipología de conventos masculinos. Mientras que el monasterio de San Jerónimo el Real fue fundado durante el bajo medievo en la periferia de la Villa, los otros seis -la Trinidad Calzada, el Carmen Calzado, los Agustinos Recoletos, el Colegio Imperial de los Jesuitas, San Basilio Magno y el Oratorio de San Felipe Neri- aparecen incorporados desde sus mismos otígenes a la ciudad, si bien los tres últimos se sitúan en el cotazón de la misma al calor de la Contrarreforma. Sobre la expansión del espacio urbano madrileño, vid. M. Molina Campuzano, Planos de Madrid de los siglos XVTI y XVTI. Madrid, 1960, plano 1; F.j. Marín Perelión y R. Más Hernández, «Madrid», en Atlas Histórico de Ciudades Europeas. Península Ibérica. Barcelona, 1994, pp. 32-61 y V. Pinto Crespo y S. Madrazo Madrazo (dirs.), Madrid. Atlas bistórico de la ciudad. Siglos IX-XIX. Barcelona, 1995.

Hipponia, LIX/1, núm. 201 (1999) 149-169 
gráfico 1). Habida cuenta de que para captar y explotar estos peculiares recursos las comunidades necesitaban de un poder político del que carecían, no es extraño que la misma existencia del clero regular urbano fuera inviable sin la articulación de unas redes clientelares muy tupidas, destinadas a captar agentes sociales directamente imbricados en los aparatos del Estado absolutista ${ }^{24}$.

\section{GRÁFICO 1. Naturaleza de los bienes donados por fundaciones de misas y memorias}

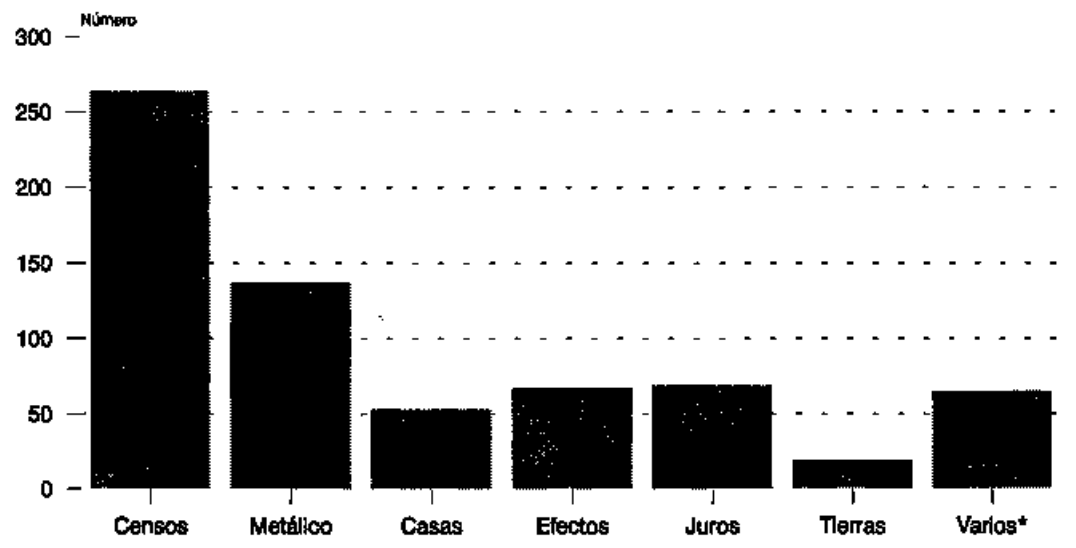

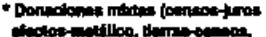
itc) $y$ otres.

La intensa feudalización que provocó la dinámica social castellana, así como la concreción espacial de las instituciones monárquicas, convirtieron a Madrid en el escenario donde se representó la apoteosis de la competencia interfeudal. En este complejo entramado, la nobleza se vio obligada a establecer relaciones sociales que tomaron forma clientelar, destinadas a preservar y am-

24 Sobre el origen nobiliario y oligárquico de los miembros de las comunidades conventuales, vid. A. Dominguez. OrtTz, Las clases privilegiadas en la España del Antiguo Régimen. Madrid, 1973, pp. 273-336. Esta tendencia también se ha constatado en el caso de los conventos femeninos italianos; a este respecto, vid. G. ZARRI, «Monasteri femminili...» y $R$. MÉNDEZ SASTRE, "La estructura conventual...», pp. 312-314. La metáfora del espacio cortesano como escenario donde los actores competian por la búsqueda de ingresos y reputación, ha sido formulada por R. SENNETT, El declive del bombre público. Barcelona, 1978, pp. 53-152.

Hispania, LIX/1, núm. 201 (1999) 149-169 
pliar su patrimonio. En consecuencia, las redes clientelares permitieron poner en contacto a las casas nobiliarias con la estructura política estatal sin destruir el marco específico de apuntalamiento de la propiedad: la familia consanguínea. Es en la articulación de este doble proceso de cierre social y apertura política de la clase feudal donde la actuación del clero regular cobra todo su sentido. Ciertamente, al aportar un discurso ideológico que remarcaba la importancia del parentesco espiritual dentro del ordenamiento social, y al ofrecer organizaciones y recursos en los que éste podría materializarse, las comunidades conventuales facilitarían la conservación de dichos patrimonios ${ }^{25}$.

Por lo que se refiere al discurso ideológico, el culto a los santos, desarrollado por la Iglesia medieval y convertido en uno de los cimientos del dogma definido en Trento, vino a estimular en los territorios católicos el desarrollo de unas redes clientelares más laxas y maleables, que ya no debían constituirse necesariamente en torno a un linaje determinado, sino que podian establecerse a través de la vinculación espiritual de sujetos concretos a un mismo intermediario celestial. La difusión de esta concepción concedió a los vínculos así formados un grado de flexibilidad suficiente para superar la aparente contradicción entre el cierre social y la apertura política de las familias nobiliarias, al tiempo que vino a otorgar un nuevo elemento de legitimación a las relaciones de parentesco artificial. De otro lado, los aparatos ideológicos no discursivos provistos por el clero regular concedieron a unas unidades familiares cada vez más cerradas la posibilidad de evitar la ruptura de su estructura patrimonial, al garantizar la supervivencia de algunos de sus miembros mediante la ocupación de cargos eclesiásticos. A la vez, y desde una perspectiva más amplia, las instituciones conventuales se convirtieron en espacios de relación social que facilitaron el contacto y establecimiento de relaciones entre diferentes bandos-linaje y facciones cortesanas ${ }^{26}$. Por último, las necesidades estructurales que llevaban a ampliar continuamente sus clientelas para obtener así tecursos económicos y políticos, y la mayor flexibilidad del propio discurso ideológico del clero regular frente al acuñado por la nobleza

25 Las transformaciones que en el tránsito de la Edad Media a la Moderna sufren tanto las relaciones de parentesco como el sistema familiar de transmisión de propiedad en la Europa mediterránea, pueden seguirse a través de B. Clanero, Majorazgo. Propiedad feudal en Castilla 1369-1836. $2^{\mathrm{a}}$ ed. Madrid, 1989; G. DeLlLLE, Famille et proprietè dans le Royaume de Naples (XVeXIXe siètles). Roma-París, 1985 y J. CASEY, Historia de la familia, Madrid, 1990.

26 Por lo que se refiere al culto de los santos y a su papel como intermediatios celestiales, pueden consultarse los estudios de J. Le GoFf El nacimiento del purgatorio. Madrid, 1981; J. DeluMEAU, Le péché et la peur. La culpabilisation en Occident (XIIle - XVWhe siècles). París, 1983, pp. 416446; A. GUERREAU-JALABERT, "El sistema de parentesco...», passim y nuestro trabajo "Religiosidad...", pp. 286 y ss. Respecto a la articulación de los bandos-linaje en la Castilla feudal, deben verse $A$. MACKAY, "Ciudad y campo en la Europa medievaly, Studia Historica, II: 2, 1984, pp. 27-53, esp. 45 y ss.; J.M. Monsalvo AnTón, El sistema politico concejilL El ejemplo del señorio medieval de Alba de Tormes $y$ su concejo de villa y tierra. Salamanca, 1988 y M.T. PÉREZ PICAZO y G. LEMEUNIER, "FForme di potere locale nella Spagna moderna e contemporanea: dalle fazioni al cacichismo nel regno di Murcia (secoli XVIXIX)M. Cheiron, 5, 1986, pp. 105-129. 
laica en torno a la idea de una nobilitas certada, abrirían vías de acceso y promoción a clases urbanas en ascenso (abogados, médicos, grandes comerciantes...) a través de h labor educativa de algunos colegios pertenecientes a ciertas órdenes, la creación de congregaciones y cofradías, así como la captación de miembros de los grupos más destacados dentro de las feligresías partoquiales.

Una de las fórmulas principales de formalización de estas redes clientelares fue la constitución de escrituras de fundación de memorias perpetuas. Estos contratos establecidos entre diferentes agentes sociales y hs comunidades conventuales suponían la normalización, efectuada en el momento de testar, de una relación preexistente, dado que de ordinario el fundador estaba firmemente vinculado al convento por lazos familiares, la asistencia asidua a los servicios religiosos o la pertenecia a alguna de las cofradias y congregaciones articuladas en torno al recinto monástico. La fundación de memorias de misas establecía un intercambio de servicios espirituales por rentas y/o bienes ${ }^{27}$.

Obviamente, ante la limitación del espacio social cortesano, la captación de clientelas dio lugar a una intensa pugna entre las diversas órdenes religiosas; a la vez, al centrarse esta lucha en torno a la cura de almas, el clero regular entró en directa confrontación con los eclesiásticos seculares, quienes no estaban dispuestos a perder una buena parte de los recursos a extraer de sus feligresias. Las tensiones provocadas por esta pugna no sólo se manifestaron en los propios contenidos ideológicos y propagandísticos utilizados por los frailes, sino también en los recursos empleados por éstos para proyectar dichos contenidos sobre la sociedad madrileña ${ }^{28}$.

La profusión de procesiones, sermones y contactos personales que divulgaban en calles, iglesias y casas los contenidos de la ortodoxia tridentina y ensalzaban las bondades de las diferentes devociones, abonaron un terreno que muy pronto fructificaría con la eclosión de numerosas y prestigiosas fundaciones de misas, que se vieron acompañadas de impresionantes donativos. Además, el

27 En la documentación consultada, a estos fundadores se les designa con el término de patronos, siendo sin embargo clientes dentro de las redes establecidas por los conventos. De este modo, cada instituto de regulares, convertido en un auténtico patrón de patronos, permite a éstos acceder a la mediación que el santo de su advocación particular ejerce ante la misma divinidad. A si, la red clientelar terrenal se legitima doblemente, al enlazarse con otra sobrenatural que se pretende organizada según sus mismos principios y al hacer posible la articulación entre ambas a través de un intermediatio concreto en la corte celestial.

28 Este hecho desató una feroz competencia entre los distintos institutos, concretada en numerosas polémicas sobre la antigüedad y preeminencia de las órdenes, en la profusión de obras de carácter hagiográfico y en la presión que las congregaciones ejercieron sobre las Cortes para que éstas defendieran la canonización de sus figuras más destacadas. De resultas de esta presión, entre 1602 y 1655 se incoaron numerosos procesos de canonización de señeros representantes de las órdenes castellanas $T$. EgIDO, «Religiosidad "popular" y Cortes tradicionales en Castillas, en C. Álvarez SANTALÓ, MBUXÓ, M.J. BuXó i REY y S. RoDRjGuez BECERrA (Coords.), La rekgiasidad popular. Vol. II. Barcelona, 1989, pp. 96-110, p. 104. En cuanto a la literatura hagiográfica, véase el capitulo Santos contra santos en S. BERT'TWU, Rebeldes, kbertinosy ortodaxos en e/ Barroco. Barcelona, 1984, pp. 89-109. Este fenómeno también se manifestó en el terreno de la iconografia religiosa. S. SEBASTíiN, Contrarnformay Barnoco. Madrid, 1981, pp. 239-308.

Hispania, LIX/1, núm. 201 (1999) 149-169 
desenvolvimiento del propio sistema no hizo sino acrecentar el prestigio del que ya gozaban estos institutos, favoreciendo así su autorreproducción, a través del ingreso en ellos de miembros de la clase feudal y de la realización de voluminosas fundaciones mediante las cuales los grupos ascendentes también asumían los postulados de la ideología difundida por los regulares ${ }^{29}$.

La evolución de las fundaciones de memorias aparece teflejada en el gráfico 2. Las dos fases sucesivas de expansión (1580-1609) y estabilización (1610-1689) demuestran con nitidez el paulatino enraizamiento en Madrid de las relaciones que dieron lugar al nacimiento de las clientelas conventuales. Si además atendemos a la trayectoria seguida por la curva de capitales donados por este concepto, empiezan a clarificarse las características de la composición social de dichas

\section{GRÁFICO 2. Evolución de las fundaciones de misas de siete conventos madrileños.} (Por décadas).

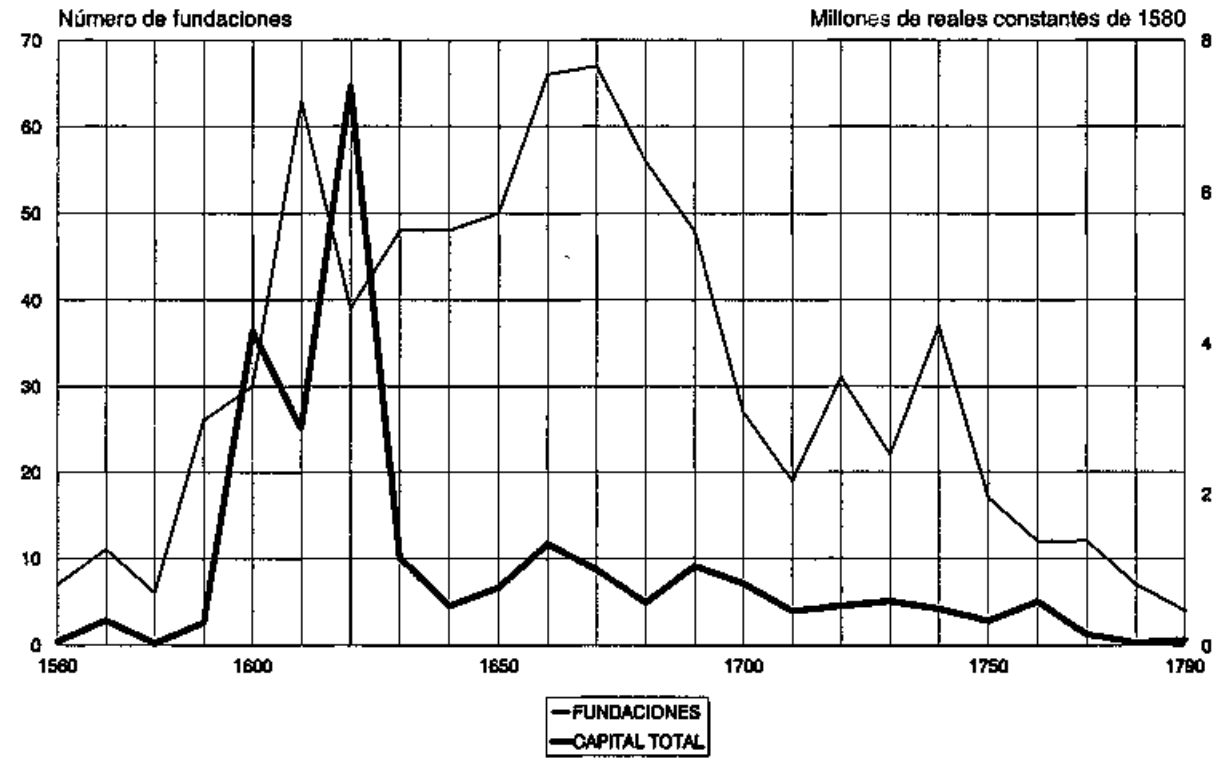

29 La cuantía de las donaciones dependia del número de misas encargadas por sus clientelas y de la decisión de éstas de ser enterradas en las propia iglesia conventual. Así, por ejemplo, en 1633 don Gonzalo de Menchaca, regidor y procurador en Cortes de la ciudad de Sevilla, ordenó que a su muerte se celebrasen 73 misas perpetuas en San Basilio y 2.500 de cuerpo presente en los altares privilegiados de la Villa, que se repetirian en los ocho años siguientes. A.H.N., Clero, Lib. 6.899 , ff. $65 \mathrm{t} .-82 \mathrm{v}$. Por lo que se refiere al lugat del sepelio, el 70 por ciento de los fundadores de los Agustinos Recoletos dispusieron en sus testamentos que éste tendría lugar alli, mientras que en el caso de San Basilio dicho porcentaje se situó en el 41,37. Ibidem, Libs. 6.780-7.801 y 6.894-6.925. 
clientelas. En este sentido, se constata una disminución del capital unitario por memoria, lo que permite inferir una creciente generalización de las mismas no sólo entre las distintas fracciones de la clase dominante, sino también entre los miembros de los grupos sociales en ascenso ${ }^{30}$.

Por lo que se refiere a la caracterización social de las clientelas conventuales (Cuadro 1), seis son los grupos fundamentales sobre los que descansa su estructura, de acuerdo al siguiente orden de importancia: la nobleza, el propio clero regular, el personal de la Casa Real, los oficiales de los Consejos ${ }^{31}$, las profesiones liberales -abogados, médicos y escribanos- y, por último, los eclesiásticos seculares. Sólo estos seis grupos representaban el 53 por ciento de los 267 casos en los que conocemos la procedencia social del fundador. Pero tan relevante como el volumen de estos grupos es la escasa importancia de otros, como mercaderes, artesanos y labradores, pues entre los tres no llegan a alcanzar a ninguno de los grupos de cabeza. Ahora bien, estas pautas pueden matizarse si descendemos a un estudio más promenorizado de cada instituto, el cual permite entrever un cierto grado de especialización en la captación clientelat. Así, mientras que ciertos cenobios muestran una vocación decididamente nobiliaria -San Jerónimo o el Colegio Imperial-otros evidencian una mayor permeabilidad con respecto a las clases emergentes, convirtiéndose en potenciales plataformas de ascenso social, como San Basilio, el Carmen o la Trinidad Calzada ${ }^{32}$.

Esta captación clientelar se realizó a través de dos medios específicos e interrelacionados: la vinculación de ciertos linajes a determinados conventos y las actividades proselitistas desarrolladas por los regulares. Por lo que se refiere

30 La única distorsión que se observa es la producida en la década 1620-29, en la cual la curva de capitales donados supera a la de número de fundaciones. Sin embargo, este hecho se explica porque en el referido arco temporal el Colegio Imperial de los Jesuitas recibió más de siete millones de reales por este concepto, lo que evidencia la predilección de la aristocracia por dicha orden, similar a la ya conocida para otros territorios de la Europa católica reformada y de la que nos hablan L. CHATEL.JER, «A l'origine d'une société catholique. Le tôle des congregations mariales aux XVIe-XVIIIe siècles». Histoire, Economic et Société, 2, 1984, pp. 203-220; V. PrESS, «Protezione e clientele nell Sacro Romano Imperio Germanico». Cheiron, 5, 1986, pp. 6787, especialmente 68-75 y M. A. VISCEGLIA, Il bisogno di eternità. I comportamenti aristocratici a Napoli in Età Moderna. Nápoles, 1988, pp. 107-139.

31 Al clasificar a los fundadores que tuvieron algún tipo de vinculación con los consejos reales y el Concejo de la villa, hemos distinguido entre oficiales y empleados. La primera categoria designa a todos aquellos individuos que ocupaban las altas esferas de la organización administrativa de ambos organismos (consejeros, regidores, etc.), mientras que la segunda hace referencia al «personal subalterno» que trabajaba en ellos. De esta diferencia da cuenta J. FAYARD en su obra Los miembros del Consejo de Castilla (1621-1746). Madrid, 1982, pp. 24-30. Igualmente, esta autora ha constatado la preferencia de los oficiales del Consejo de Castilla por los establecimientos de regulares a la hora de fundar memorias de misas y ser enterrados; ibidem, pp. 478491.

32 Una aproximación a la localización espacial de las clientelas de los conventos madrilenos puede verse en «Religiosidad..., mapas $2,3, \mathrm{y} 4$.

Hispattia, LIX/1, núm 201 (1999) 149-169 


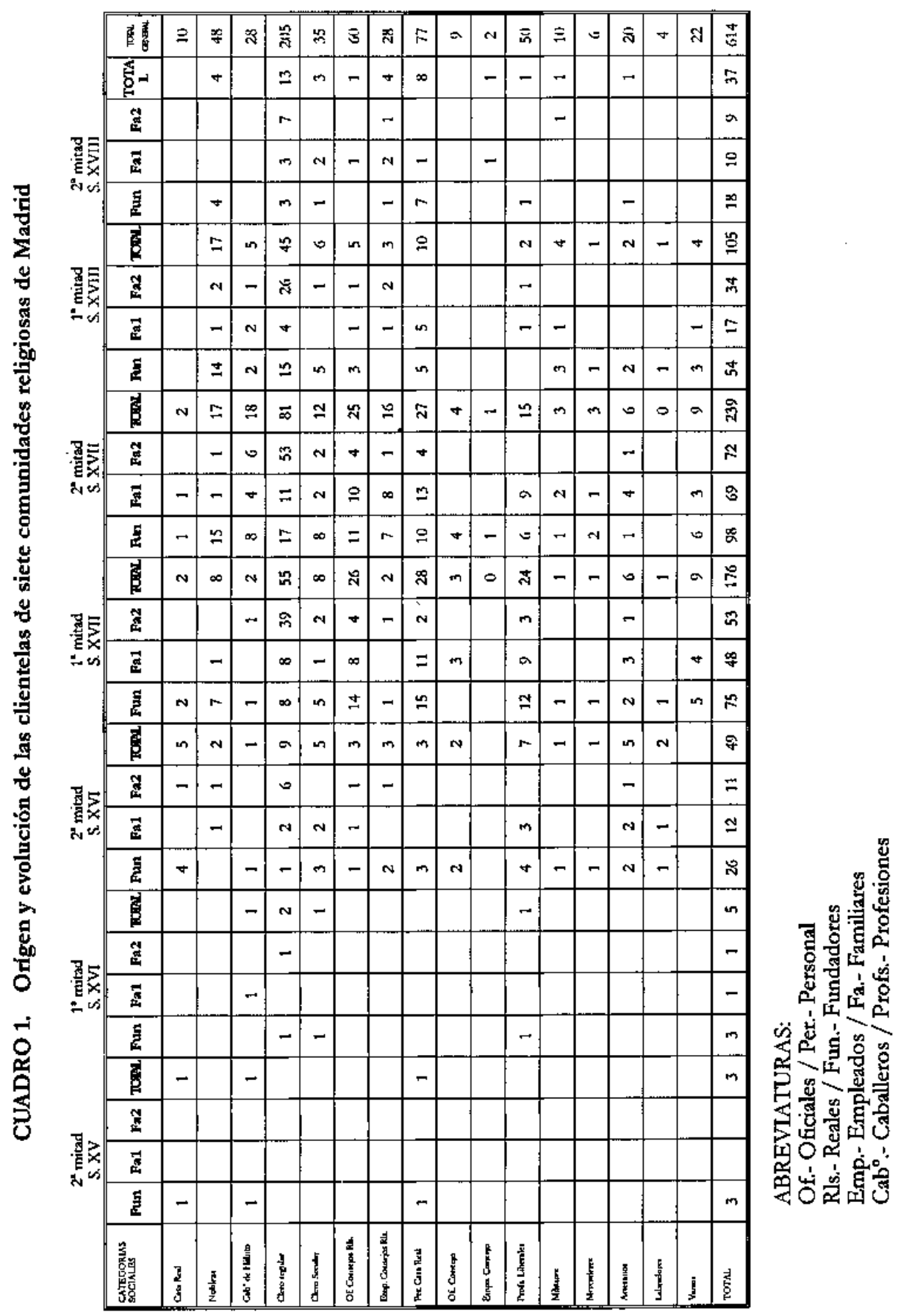

Hippania, LIX/1, núm. 201 (1999) 149-169 
al primero, los frailes ocupan la segunda posición dentro de los parientes más allegados a los impositores de memorias (Familiar 1), lo que confirma la integración física de miembros pertenecientes a estas familias en el interior de los claustros y explica su predilección por los mismos a la hora de realizar donativos. En cuanto al segundo, h presencia abrumadora de religiosos en las escrituras de fundación en calidad de albaceas y confesores (Familiar 2), constituye un claro indicador de la habor propagandística desarrollada tanto en el interior de sus iglesias como en el espacio urbano. Dicha actividad de los monjes en la calle, determinó la configuración de unas feligresias definidas por situatse espacialmente en las áreas más cercanas a las sedes conventuales ${ }^{33}$.

No obstante, este modelo global de configuración clientelar experimentó una profunda transformacióna partir de 1690, década en la que se inicia una aguda crisis manifestada en la disminución del número de memorias, la deserción de las clases ascendentes y la consiguiente aristocratización de los fundadores de misas perpetuas. Estos procesos aparecen asimismo reflejados en el Gráfico 2 y el Cuadro 1, donde se aprecia un descenso de las fundaciones y un aumento del capital donado por este concepto, que ahora procede casi exclusivamente de la alta nobleza.

Las tazones que explican el declive de este modelo han de buscarse una vez más en los cambios estructurales que se produjeron en Castilla en esta fase de la transición al capitalismo. Recordemos que la derrota histórica sufrida por el clero regular en la propia expansión feudal castellana se tradujo en su reubicación dentro de la estructuta económica -tendencia a emplazarse en los canales de distribución de renta feudal-y en una mayor especialización en los procesos ideológicos de vertebración e integración horizontal de la clase dominante. Esta situación específica de los regulares dentro de la formación social castellana se explica asimismo por la estructura económica imperante en la época Moderna. Sin embargo, a partir del siglo XVIII se producirán una serie de cambios estructurales tendentes a la paulatina «absolutización» de la propiedad de los medios de producción, haciendo que la explotación y la acumulación vayan adquiriendo un carácter cada vez más económico, de ahí que el poder político pueda distanciarse del entramado productivo, al tiempo que se concentra en aparatos de Estado progresivamente centralizados ${ }^{34}$. Aunque estas

33 Esta misma preferencia ya ha sido constatada en Francia e Italia para el mismo periodo; a este respecto, wid M.VOVELLE, Piété barogue et déchristianisation en Provena au XVIIle siecle. Marsella, 1978; P. Chaunu, La mort à Paris, XVIe, XVIle et XVIIIe süectes. París, 1978 y M.A. ViscecLis, Il bisogna..

34 Por lo que se refiere al proceso de «absolutización» de la propiedad de los medios de producción que alcanzará su culminación en el siglo XIX, vid. M.T. PÉREZ PICAZO y G. LEMEU. NIER, El proceso de modernización de la región murciana (siglos XVI-XIX). Murcia, 1984, pp. 250-273; P. Rutz TORREs, «La propiedad de la tierra en la transición al capitalismo». Debats, 15, 1986, pp. 19-24; B. YUN CASALILAA, Sobre La transición al capitakismo en Castilla. Economia y sociedad en Tierra de Campos (1500-1830). Salamanca, 1987, pp. 601-636 y J. CRUz, Gentlemen, Bourgois, and Revolutionaries. Political change and cultural persistence among the Spanish dominant groups, 1750-1850. Cambridge (N.Y), 1996. En lo que respecta al proceso de centralización política, vid. P. FErNÁNDEZ ALBA. LADEJO, «La Monarquía de los Borbones", en Fragmentos de Monarguia. Madrid, 1992, pp. 353-454 y J. FonTANA, La crisis del Antiguo Régimen. 1803-1833. Barcelona, 1979.

Hispania, LIX/1, núm. 201 (1999) 149-169 
transformaciones no implicaton una disminución del peso ideológico sobre la estructura social, sí modificaron sus contenidos (interiorizados e individualizados) y las organizaciones y recursos encargados de suministrarlos y conservarlos (más jerarquizados, y sometidos a las decisiones de un poder político central al que no estaban en condiciones de desafiat).

En este nuevo entramado social el clero regular nacido del feudalismo dejó de desempeñar un papel relevante, dado que en este siglo la Monarquía y la clase dominante laica van a apostar decididamente por los aparatos ideológicos de una Iglesia cuyo centro de gravedad se desplaza cada vez más hacia el clero secular ${ }^{35}$. Una vez que los regulares quedaron definitivamente circunscritos al ámbito de la articulación interna de la clase dominante, las transformaciones sufridas en la estructura social y la agudización de las contradicciones inter. nas que arrastraba su modelo de integración acabaron por minar los cimientos de los conventos cortesanos. Por una parte, la progresiva "absolutización» de los poderes efectivos de la aristocracia y la naciente burguesía sobre los medios de producción y la creciente concentración del poder político en un Estado centralizado, hicieron que el entramado clientelar que mediaba entre los diferentes poderes concurrentes experimentase una transformación radical, en la que la ideología y los aparatos no discursivos proporcionados por los regulares, a fin de concretar un tipo de redes clientelares fundamentadas en el parentesco espiritual, dejaron de tener sentido. Por otro lado, las nuevas vías de promoción social abiertas por las transformaciones económicas del Setecientos llevaron a que gran parte de las clases en ascenso abandonasen un modelo ideológico, el de los regulares, que llevaba implícita la contradicción de auspiciar su integración pero nunca más allá de la subordinación a una aristoctacia cada vez más cerrada ${ }^{36}$.

Esta profunda deslegitimación ideológica desencadenó una importante pérdida de recursos sociales y políticos, que a su vez acabó determinando la modificación de su organización patrimonial. Cada vez ingresaban menos individuos en los claustros y el número de fundaciones a favor de estas comunidades también se estaba reduciendo ${ }^{37}$; ambos fenómenos acarrearon la paralización de las donaciones procedentes de las dotes de los profesos y de las originadas por los encat-

$35 V i d$. para el caso madtileño, V. PINTO CRESPO, «Una reforma desde arriba: Iglesia y religiosidad", en EQtrPo MADrID, Carlos III..., pp. 155-188 y «La Iglesia, organización y presencias en Madrid. Atlas bistórico..., pp. 296-311. Una perspectiva más general en W. CALLAHAN, Iglesia, podery saciedad en España, 1750-1874. Madrid. 1989, pp. 11-182.

36 Este proceso también ha sido comprobado en el ámbito de las instituciones educativas tegentadas por los regulates por J.S. AMELANG, La formación de una clase dirigente. Barcelona 14901714. Barcelona, 1986, pp. 165-166 y J.F. MARTín De LAs MULAS y B. Tremiño, "La enseñanza en la Edad Moderna, siglo XVI-XIX”, en Madrid Atlas bistórico..., pp. 340-349.

$37 \quad$ La reducción del tamaño de las comunidades religiosas en la segunda mitad del siglo XVIII ya ha sido constatada para toda la Corona de Castilla por J. SáEZ MARÍn, Datos sobre la Iglesia española contemporánea (1768-1868). Madrid, 1975, pp. 164-256. El caso concreto de Madrid, cuyos frailes y monjas se redujeron en un 26,37 por ciento entre 1757 y 1808 , en J. IzQUIERDO MARTiN, J.M. López Garcia y otros, "La reforma...» y V. PinTo CresPo, "La Iglesia, organización y presencian, en Madrid Atlas bistorico..., pp. 296-311, gráfico 93.

Hiqpanic, LIX/1, núm. 20 t (1999) 149-169 
gos de ceremonias religiosas. Además, la consiguiente pérdida de apoyos políticos condujo al detrumbe de la vieja estructura rentística de estos conventos, pues al no disponer ya de autoridad e influencia en los aparatos centrales del Estado absolutista y el ayuntamiento, las rentas devengadas por los censos consignativos, los jutos y los efectos se desplomaron; todo ello se vio agtavado por el hundimiento de las Haciendas Real y municipal, así como por la crisis generalizada del sistema censal ${ }^{38}$.

La concurrencia de todos estos fenómenos significó la ruptura del proceso que garantizaba la supervivencia del clero regular. Así las cosas, la única vía que quedaba abierta para estos conventos consistió en reorganizar su gestión patrimonial, haciéndola descansar ahota en la adquisición de fincas urbanas y rústicas, vía que si bien fue emprendida tardiarnente cuando la estructura de la propiedad en Madrid y su Tierra ya estaba casi configurada, terminó convirtiendo al clero regular en un directo competidor de sus aliados naturales en el mundo laico ${ }^{39}$. Finalmente, la alianza de clases que se produjo durante la revolución liberal entre diferentes fracciones de la antigua clase feudal y la burguesía acabó desahuciando al clero regular, eliminando de esta forma a uno de los baluartes del absolutismo, al tiempo que conseguía sanear la nueva Hacienda Pública mediante la definitiva expropiación de los bienes pertenecientes a su antiguo competidor ${ }^{40}$.

38 Acerca del derrumbe simultáneo del crédito público y privado, vid. A. Castullo PINTADO, «Los juros en Castilla: apogeo y fin de un instrumento de créditon Hippania, 23, 1963, pp. 43-71; P. To. BOSO SANCHEZ, La deuda priblica castellana durante el Antiguo Régimen (juros). Madrid, 1987; C. DE LA Hoz GarciA, Fiscakdad y hacienda muniapal en el Madrid del sigh XVIII. Las sisas (1680 1808). Tesis de licenciatura inédita defendida en la UA.M. en 1985; E. MARTiNEZ NEIRA, Revolución y Fiscalidad Muniappal La Hacienda de ha Villa de Madrid en el reinado de Fernando VII. Madrid, 1995; J.I. MARTínEZ RuIZ, Finanzas muniazpales y crédito puiblio en la España moderna La bacienda de la ciudad de Sevilla, $1528-1768$. Sevilla, 1992, pp. 296-316; B. YUn CASALULA, Sobre la transición..., pp. 370396 y F. ANDRÉs ROBRES, «Aristocracia y censos en Valencia. (A un siglo de la expulsión)», en Homenatge al Doctor Sebartià Gartía Martinez. Valencin, 1988, pp. 215 227; C. GARCiA GARCí, La misis de has baciendas locales: de la reforma administrativa a la rfforma fiscal Valladolid, 1996 y J.M. LÓPEZ GARCiA (Dir.), El impacto..., pp. 300-334.

39 La importancia del cleto como propietario en la Tierra de Madrid a finales del Antiguo Régimen ha sido constatada por S. MADRAzo MADRAzo y otros, «La Tierra de Madrid», en Madrid en la Éoca moderna.., pp. 27-68, esp. 54-61; en cuanto al patrimonio inmobiliario de los conventos de la Corte, wid. R MÉNDEZ SASTRE, «La propiedad urbana del clero regular madrileño. Primeros resultados e hipótesis para una futura investigación», en E. SARASA y E. SERrano (Eds), Señorío y Fezdalismo en la Peninsula Ibérica. Siglas XII - XIX. Vol. III. Zaragoza, 1994, pp. 173-196. Por último, la cronología y características del proceso de configutación patrimonial de estos conventos pueden encontrarse en JF. MARTín DE LAS MULAS REGULLO, La estructura del clero regular madrileño: una apraximación al estudio de Las ecomomias monánticas en Madrid (1547 - 1844). Tesis de licenciatura inédita defendida en la U.A.M. en 1990 y J.M. Lópéz GarCía y S. Madrazo Madrazo, "A Capital Ciby..." p. 133.

Sobre la relación existente entre desamortización, afianzamiento de la nueva clase dominante surgida de la fusión entre burguesia y aristocracia y saneamiento de la Hacienda Pública del estado liberal, vid. J. FONTANA, «La desamortización de Mendizábal y sus antecedentes», en A. Garcia Sanz y R. Garrabou (eds.), Histotia agratia de la España contemporánea. I. Batcelona, 1985, pp. 219-244. El caso madrileño ha sido estudiado por J. SMMON SEGURA, Contribución al estudio de la desamortización en España. La desamortización de Mendizábal en la provincia de Madrid.

Hipanja, LIX/1, núm 201 (1999) 149-169 
FUENTES

\section{Abreviaturas: AHN: Archivo Histórico Nacional (Madrid).}

\section{AHPM: Archivo Histórico de Protocolos de Madrid.}

San Jerónimo el Real.

AHN Cleto: Libro 7.487.

Legajos $4.081,4.082$ y 4.084 .

Nuestra Señota de la Trinidad.

AHN Clero: Libros 7.938, 7.940, 7.945, 7.951, 7.952, 7.953, 7.963, 7.970 y 7.996 .

Legajos 4.203, 4.204, 4.208, 4.210, 4.211, 4.212, 4.213, 4.215, 4.216 (1-2), 4.217, $4.218,4.219$ y 4.220 .

Nuestra Señora del Carmen.

AHN Clero: Libros 6.981, 6.990, 7.008, 7.015, 7.017, 7.019, 7.027, 7.034, 7.036, $7.041,7.043$ y 7.057

Legajos 3.801, 3.802, 3.803, 3.804, 3.805, 3.806, 3.807, 3.808 y 3.809 .

AHPM: Protocolos $2.756,15.845$ y 24.882 .

Agustinos Recoletos (Copacavana).

AHN Clero: Libros $6.780,6.781,6.782,6.783,6.784,6.786,6.787,6.788,6.801,6.802,6.808$, $6.809,6.810,6.811$ y 6.813 .

San Basilio Magno.

AHN Clero: Libros $6.894,6.895,6.896,6.898,6.899,6.900,6.901,6.902,6.903,6.904,6.905$, $6.907,6.908,6.909,6.910,6.911,6.912,6.913,6.914,6.915,6.916,6.917,6.918,6.919$, $6.920,6.921,6.922,6.923,6.924$ y 6.925 .

Oratorio de San Felipe Neri.

AHN Clero: Libro 7.814 .

Colegio Imperial de la Compañía de Jesús.

AHN Jesuitas: Libros 99,298 y 360.

Legajos 606,745 y 748 .

Madrid, 1969; R. MÁs HERNÁNDEZ, «La propiedad urbana en Madrid en la primera mitad del siglo XIX), en Primer Cologuio sobre Madrid en la Sociedad del Siglo XIX. Madrid, 1986, vol I, pp. 2387; del mismo autor, «La valoración de la ciudad y la propiedad del caserío, 1830-1850», en Madrid. Atlas bistórico..., pp. 118-121; J.M. LÓPEZ GARCiA, «El ocaso de los institutos de tegulates castellanos en las postrimerías del Antiguo Régimen». Hacienda Pública Española, 108-109, 1987, pp. 311-325 y J. BEL LO, Frailes, intendentes y poltitios. Los bienes nacionates, 1835-1850. Madrid, 1997.

Hispartia, LIX/1, núm 201 (1999) 149-169 